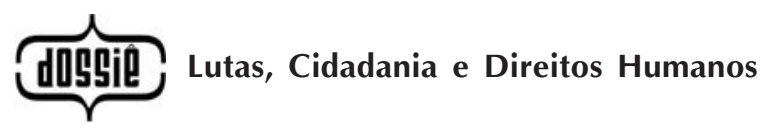

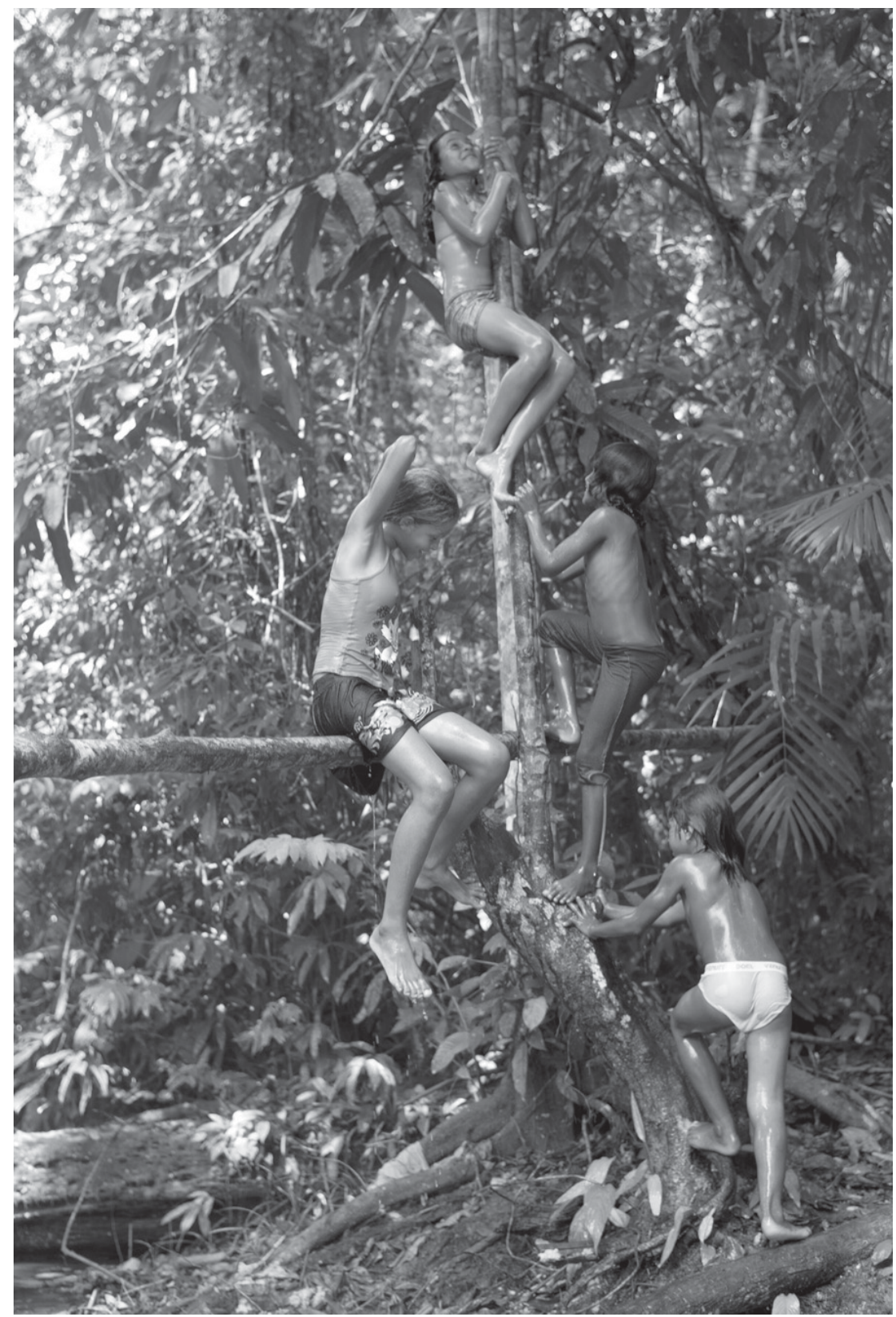

Fotografias: João Roberto Ripper 


\title{
Aportes marxistas para la comprensión contemporánea del problema de la igualdad
}

\author{
Contribuições marxistas para uma compreensão \\ contemporânea do problema da igualdade \\ Marx's contributions to understand the contemporary \\ problem of equality
}

\section{Paula Vidal Molina*}

\begin{abstract}
Resumen - En este artículo se ofrece una reflexión sobre la existencia, en la obra de Marx, de una preocupación por la igualdad y la justicia social, que vuelve a tomar significación frente a la crisis civilizatoria a que nos arrastra la dinámica del capitalismo, para delimitar algunos de los elementos que ayudan a construir y delinear un proyecto histórico societario que evite la catástrofe. La obra de Marx es donde más claramente se relaciona la desigualdad con la lógica del capital de valorizarse constantemente a sí mismo a expensas del trabajo no retribuido al obrero. Especialmente en su Crítica del Programa de Gotha se visualiza una delimitación de los criterios de distribución que existirán en el camino para alcanzar una sociedad postcapitalista: los principios de contribución y necesidad. El primero se ubica en la fase de transición hacia el comunismo, y el segundo es realizable en el marco de una sociedad comunista. Solo en este nivel, en la sociedad comunista, la humanidad podrá vivir la plena emancipación.

Palabras clave: igualdad; justicia social; capitalismo; Marx.
\end{abstract}

Resumo - Neste artigo é oferecida uma reflexão sobre a existência, na obra de Marx, de uma preocupação pela igualdade e a justiça social, que volta a ganhar significado diante à crise civilizatória à qual nos arrasta a dinâmica do capitalismo, com o objetivo de delimitar alguns dos elementos que ajudam a construir e traçar um projeto histórico societário que evite a catástrofe. É na obra de Marx onde mais claramente se relaciona a desigualdade com a lógica do capital de autovaloração constante a custo do trabalho não pago ao operário. É especialmente na Crítica ao Programa de Gotha que se visualiza uma delimitação dos critérios de distribuição que existirão no caminho para alcançar uma sociedade pós-capitalista: os princípios de contribuição e necessidade. O primeiro encontra-se na fase de transição ao comunismo e o segundo é realizável no marco de uma sociedade comunista. Só neste nível, na sociedade comunista, a humanidade poderá viver a sua plena emancipação.

Palavras chave: igualdade; justiça social; capitalismo; Marx.

Abstract - We offer a reflection about existence, in the works of Marx, of the concern for social equality and justice, that takes significance once again in front of the civilization crisis to which the dy-

\footnotetext{
* Doutora em Servicio Social de la Universidade Federal do Rio de Janeiro (UFRJ) e docente de Trabajo Social, Facultad de Ciencias Sociales, Universidad de Chile. Correspondência: Avenida Ignacio Carrera Pinto 1045. Ñuñoa. Santiago. Chile. E-mail: <pvidal71@yahoo.com>.
} 
namics of capitalism drags us, to delimit some of the elements that help us to build and trace a historical societary project that avoids a catastrophe. In Marx's work relies the clearest relationship between the inequality and the capital's logic of constantly self-valorize at the expense of unpaid work to the laborer.Specially, on his Critique of the Gotha Programme he visualizes a delimitation of the criteria of distribution that will exist in the way to reach a post-capitalist society: the principles of contribution and necessity. The first one is located in the transition phase towards communism and the second one is achievable under a communist society. Only at this level, in the communist society, humanity will be able to live in full emancipation.

Keywords: equality; social justice; capitalism; Marx.

\section{Por la necesaria vuelta a la emancipación}

La nueva configuración que adquiere el capitalismo y sus manifestaciones en el momento actual es evidente. Ella se viene estructurando principalmente a partir de la década de los años setenta del siglo XX. Por tal motivo, desde diversos frentes se proclama que tales características ya no expresan acontecimientos de una coyuntura, ni transformaciones pasajeras, marcan una nueva época histórica. Aquí, lo que se pone en juego es la viabilidad del propio sistema dominante, a pesar de que éste se las ha arreglado en el pasado para sobrevivir y revigorizarse (a costa de innumerables devastaciones), su futuro - de sobrevivir - será bajo un monstruoso escenario.

Las características que ha adquirido esta nueva configuración hacen que emerja con mayor fuerza la idea de que el capitalismo es la causa de los procesos de regresión planetaria que se vienen viviendo, y diverso es el lenguaje utilizado para dar cuenta de ello. Algunos hablan de que el capitalismo ha llegado a sus límites, otros de una crisis civilizatoria, de una crisis estructural del sistema como un todo, o del estado de barbarie en que estamos sumergidos. En todo ello, cabe resaltar que cada concepto, cada metáfora refiere a un estado complejo de la realidad, y que su hilo común es la absoluta certeza de que no queda más que esperar el colapso para la humanidad, si es que nos mantenemos en este camino.

La pobreza y desigualdades persistentes, al interior de y entre pueblos, la destrucción ambiental, la imposibilidad de extender a toda la humanidad el patrón de consumo de masas de los países centrales debido a los escasos recursos naturales, la crisis alimentaria producto de la mala distribución de los recursos entre las naciones, el desempleo crónico o estructural junto al empleo informal-precarizado en países centrales y periféricos, la disminución de los Estados en lo que al resguardo y promoción de los derechos políticos, económicos-sociales y culturales de sus ciu- 


\section{ReVistg all paUtg}

\} APORTES MARXISTAS PARA LA COMPRENSIÓN CONTEMPORÁNEA - MOLINA, P. V.\}

dadanos compete, y la lógica del capital que implica continuar produciendo a partir de la necesidad de su valorización, desembocando muchas veces en sangrientas guerras o en recurrentes crisis del capital con nefastas consecuencias para los sectores más desposeídos y vulnerables, son sólo algunas de las consecuencias que develan los efectos paradojales e irracionales los límites del sistema - del capitalismo y su marcha destructora. Este fenómeno no sólo proporciona importantes razones para repudiar el presente y futuro que ofrece el capitalismo como modelo social, sino, también, obliga a buscar urgentemente alternativas que promuevan y establezcan nuevas pautas de sociabilidad para una futura sociedad.

Esta desenfrenada carrera hacia el abismo materializa representaciones monstruosas de sociabilidad, como la gran contraparte del cuadro racional de desarrollo para la humanidad, que implicó también el capitalismo. Sin duda, éste fue un avance civilizatorio, pero el siglo XX mostró que el capitalismo agotó dicha posibilidad para la humanidad.

Mészáros (2004), lo enuncia como una humanidad enfrentada hoy a la producción destructiva, esto es, al "peligro potencial de autoaniquilación en razón de la aparente incontrolabilidad de su modo de reproducción sociometabólica bajo el dominio del capital". Es decir, el desarrollo de las fuerzas productivas durante el siglo XX, bajo las actuales condiciones, se han transformado en fuerzas destructivas (al ser utilizadas irresponsablemente). Hobsbawn (2006), en esta misma línea argumental, hizo el Ilamado a mudar urgentemente la comprensión simplista del presente, acerca de la situación planetaria, interpelándonos frente a la responsabilidad de optar por modificar el camino de convivencia mutua que hemos construido. Todo lo cual obliga a cambiar - en el siglo XXI - la fórmula de organización mundial de la economía basada en el capitalismo (con su impulso de crecimiento ilimitado), y abandonar con ello también la vieja creencia - impuesta no solo por los capitalistas - en un futuro de crecimiento ilimitado a base de la extracción de los recursos del planeta. El interés de Hobsbawn (2006) - a aunque no solo suyo - fue también señalar los desafíos de una economía en el siglo XXI con unos ejes que hablaran - a lo menos como bosquejo - de un nuevo modelo societario. Para él, la justicia social, la vida digna para todos y la realización de las potencialidades inherentes a los seres humanos, serían los ejes centrales que ponen el bienestar y la justicia social como núcleo de las prioridades sociales y morales de una sociedad buena y humana.

En este contexto, se requiere elaborar "antídotos" que apunten a superar el capitalismo. Por ello, requerimos apropiarnos de su lógica, estudiada ya por Marx, pero también identificar -junto con lo que se mantiene de ésta - aquello del capitalismo que presenta nuevas formas en la época actual. Este primer paso introduce, asimismo, la pregunta por el tipo de sociedad a construir para las próximas generaciones, y proclama el rechazo categórico a la creencia en la posibilidad de moldear al capitalismo con 


\section{Revista pll paעtg}

\} APORTES MARXISTAS PARA LA COMPRENSIÓN CONTEMPORÁNEA - MOLINA, P. V. \}

un rostro "más humano" ${ }^{1}$, reformulado sobre "bases éticas". Sin duda, estas bases se ubican en las antípodas del modo natural y salvaje de existir del capitalismo, donde el lucro, explotación, competencia y egoísmo, son irreconciliables con el buen sentido de lo "humano".

Se aprecia entonces - y cada vez con mayor fuerza - en intelectuales, en actores y movimientos sociales un creciente escepticismo, descontento y rechazo de un capitalismo reformulado, y una preocupación (con matices entre unos y otros países) no sólo por defender el terreno perdido en manos de este salvajismo, sino de fraguar un nuevo futuro. (EAGLETON, 2006).

Empero, a pesar de este positivo ánimo social e intentos esperanzadores de resistencia y construcción de otro orden, hoy se está lejos de que el liberalismo (como doctrina política y el capitalismo como sistema económico) y sus variantes, dejen de ser las encargadas de pensar y moldear la forma de llevar adelante las instituciones y las relaciones básicas de la sociedad. Bajo ese escenario, si bien el pensamiento socialista y comunista no tienen lugar en estas cuestiones, ello no significa que esta tradición, deba abstenerse de realizar la crítica al totalitarismo imperante.

Daniel Bensaïd (2009) señaló la necesidad de volver hacia las palabras de la emancipación, ayer portadoras de grandes promesas y sueños de un mejor porvenir. Pero éstas, aun cuando no lograron impedir los errores y desastres históricos cometidos, sufrieron - además - de sistemáticas campañas ideológicas que permitieron asociar palabras como comunismo, anarquía, revolución, igualdad o socialismo a terror, violencia, burocracia, totalitarismo y homogeneidad. Bensaïd nos invitaba a reparar y resignificar algunas de estas palabras - considerando y reconociendo lo ocurrido con el comunismo en el siglo XX - y comenzar a situarlas nuevamente en movimiento, nombrando la alternativa al capitalismo.

Levantaba la necesidad de reparar la palabra Comunismo, debido a su mayor sentido histórico y carga programática "explosiva", pues evoca y promete, entre otras cosas, la desmercantilización y el reparto igualitario y común de los bienes, del poder, además la solidaridad como la contraparte del cálculo egoísta y de la competencia generalizada, la defensa de los bienes naturales y culturales de la humanidad, y la lucha contra la privatización del mundo. Comunismo no es una idea pura, ni un modelo doctrinario de sociedad, o un régimen estatal y menos un modo de producción, sino que puede y debe ser el nombre de - como dice Marx - un movimiento que de modo permanente supera y suprime el orden establecido (BENSAïD, 2009), en la búsqueda de materializar la "buena sociedad". Comunismo es

\footnotetext{
${ }^{1}$ Daniel Singer (2000) ilustra muy bien esta idea al decir que la ilusión de un capitalismo sin crisis, con eterno crecimiento, o el derecho de todas las personas del mundo a gozar de un trabajo estable, permanente, con salario digno y con perspectivas de mejoras en el nivel de vida para ellos y sus hijos, es hoy una fantasía que no está de moda, inexistente en el mundo occidental.
} 


\section{AeVistg all paUtg}

\} APORTES MARXISTAS PARA LA COMPRENSIÓN CONTEMPORÁNEA - MOLINA, P. V. \}

inseparable de otras palabras que la definen y concretan, como son igualdad y justicia, solidaridad y comunidad que se entretejen a la trama - como dice Michael Löwy (1994) - de la crítica radical, irreconciliable y profunda al capitalismo.

Las palabras y la crítica deben transformarse en lo que en algún sentido Daniel Singer (2000) denominó como "utopía realista", aquella capaz de traspasar los confines del capitalismo, pero donde la utopía y el futuro se enraízan en los conflictos vigentes que brinda la sociedad contemporánea. De cierto modo esta figura de doble cara fue protagonista en las revoluciones modernas, expresando los conflictos de ese momento y el interés e intentos de ciertos sectores de la sociedad por superar la sociedad precedente (o su presente), y materializar un futuro, "la buena sociedad" a la que aspiraban.

Como sabemos, las revoluciones del mundo moderno (inglesa, norteamericana y francesa) avanzaron algunas promesas, pero especialmente fue la Revolución Francesa que buscó cumplir las promesas que implicaban las ideas de libertad, igualdad y fraternidad en la sociedad. Una vez materializadas sólo cristalizaron su incumplimiento. Es decir, palabras quebrantadas e ideales fracasados porque la misma sociedad burguesa - que las vio nacer - no pudo realizarlas para todos. Así, el(os) movimiento(s) socialista(s) y el movimiento obrero en particular, recogieron y levantaron con mayor vehemencia esas promesas, especialmente aquella que tocaba la médula del status quo de esa sociedad: la igualdad.

Ese movimiento histórico puso en el centro lo que hoy sigue siendo pertinente de situar como eje de un proyecto emancipatorio: la igualdad. La igualdad se aleja - como dice Daniel Singer (2000) - de cualquier reduccionismo de la moda actual que la asocia a conceptos vagos de equidad o lo que algunos apologistas del liberalismo llaman "igualdad de oportunidades $^{\prime 2}$. También se debe evitar identificar igualdad con una definición formal como la igualdad política o "cada persona, un voto". Tampoco con la famosa uniformidad y nivelación, ni con aquello que otros definen como igualdad jurídica. De lo anterior, no se debe olvidar que la contraparte es la desigualdad que apareció con fuerza en la agenda de los países una vez que fue imposible esconderla o simular que se erradicaba bajo el capitalismo, por más que se recurriera a justificaciones genéticas o a la biologización de la desigualdad donde el egoísmo, la competencia y el individualismo serían parte del ADN de la naturaleza humana. ${ }^{3}$

\footnotetext{
${ }^{2}$ La igualdad de oportunidades - desde la tradición liberal moderna - busca igualar las condiciones de partida de los competidores por las posiciones y los bienes sociales, para permitir posteriormente una desigualdad de resultados. Esto presenta diferencias entre los demócratas de derechas y los demócratas de izquierdas.

${ }^{3}$ Esta idea se conoce como "Darwinismo Social" que permite dar fundamento a la relación entre selección natural y competencia bajo el liberalismo económico. Se utiliza la teoría de la evolución de Darwin para defender y explicar científicamente la sociedad capitalista. Así, los que se ubican al fondo de la escala de ingresos, merecen estarlo porque no poseen los méritos y capacidades para hacerlo. Un libro que en 1976 provoca polémica por el mismo asunto es "El gen egoísta: las bases biológicas de nuestra conducta" de Richard Dawkins.
} 


\section{Un concepto para la izquierda anticapitalista... $y$ en el interior del marxismo}

La igualdad es un principio que rescatan varios autores. En ello Perry Anderson (2003) en un esfuerzo por preguntarse y dar algunas pistas acerca de la superación del neoliberalismo, enfatiza que la necesidad de hoy es que la izquierda logre vencer al neoliberalismo, y puede hacerlo atacando - entre otras cosas - en el terreno de los valores, es decir, resaltando el principio de la igualdad como criterio central de cualquier sociedad verdaderamente libre. En ese sentido, considera que los principios de la Crítica del Programa de Gotha, escrito por Marx (1979) hace más de un siglo, conservan su absoluta vigencia para la actualidad.

Asimismo, Norberto Bobbio (1996), en los años noventa adjudicaba al principio de la igualdad la función de criterio capaz de mantener la división entre derecha e izquierda. Así, alejaba una comprensión que se tenía de la izquierda: aquella que realiza una burda homologación entre igualdad e igualitarismo, en cuyo horizonte está el terminar con las desigualdades sociales; ${ }^{4}$

la distinción entre derecha e izquierda, para la que el ideal de la igualdad siempre ha sido la estrella polar a la que ha mirado y sigue mirando, es muy clara. Basta con desplazar la mirada de la cuestión social al interior de cada Estado, de la que nació la izquierda en el siglo pasado, hacia la cuestión social internacional, para darse cuenta de que la izquierda no sólo no ha concluido su propio camino sino que apenas lo ha comenzado. (BOBBIO, 1996, p. 170-171).

No es difícil - entonces - asegurar que el carácter distintivo de la izquierda histórica -socialista y comunista - es ser igualitaria, principio según Bobbio - que pone como prioridad terminar con el mayor obstáculo a la igualdad entre los hombres, esto es, el de la propiedad individual (de los medios de producción), e impulsar diversos modos y grados de colectivización de los medios de producción. Sin la superación de este obstáculo difícilmente se podrá aspirar a una sociedad de iguales;

La lucha por la abolición de la propiedad individual, por la co-lectivización, aunque no de manera integral, de los medios de producción, siempre ha sido, para la izquierda, una lucha por la igualdad, por la remoción del obstáculo principal para la realización de una sociedad de iguales. (BOBBIO, 1996, p.167).

\footnotetext{
${ }^{4}$ La tradición socialista y su principio de igualdad no se entiende cabalmente sin uno de sus precursores: J.J. Rousseau quien en "El discurso sobre el origen de la desigualdad" parte de la consideración de que los hombres han nacido iguales (ese es su estado natural) y que es la sociedad que se sobrepone al estado de naturaleza y convierte a los hombres en desiguales desde el momento en que aparece la propiedad privada.
} 


\section{AeVistg all paUtg}

\} APORTES MARXISTAS PARA LA COMPRENSIÓN CONTEMPORÁNEA - MOLINA, P. V. \}

Bobbio (1996) manifestó esta distinción y ratificó la actualidad y un futuro de trabajo en función de este principio, mientras las manifestaciones de la cuestión social sigan siendo pan de cada día.

En esa misma línea, Daniel Singer (2000) planteó que cambiar la estructura de la sociedad es la línea divisoria entre los verdaderos igualitarios de aquellos que sólo se disfrazan de tales para esconder su defensa de los privilegios. Para él, la igualdad plena, como meta de largo plazo significaba romper radicalmente con el capitalismo, ya que la incompatibilidad entre igualdad y propiedad privada de los medios de producción era "obvia" debido a la imposibilidad de igualar al empleado y al patrón.

El filósofo marxista-analítico Gerald Cohen (2001) señaló que la igualdad social es indispensable para responder la pregunta por la justicia distributiva, y que han sido tres las corrientes que se han preocupado de ello: el marxismo clásico, el liberalismo igualitarista (en la senda de Rawls) ${ }^{5}$ y el cristianismo. Cada una de estas corrientes entiende la igualdad de un modo particular, y busca su realización por medio de acciones específicas: la lucha de clases, la elaboración de un cierto tipo de constitución (reglas) y la revolución moral.

La idea de Cohen respecto de la matriz marxista, era que el valor de la igualdad junto al de comunidad y autorrealización humana eran partes fundamentales de las creencias de esta tradición: aun no habiendo desarrollado o precisado profundamente el principio de la igualdad, parecían asumirlo implícita o explícitamente, "todos los marxistas clásicos creían en algún tipo de igualdad, por más que muchos se hubieran negado a admitirlo y por más que ninguno, quizá, hubiera formulado con precisión ese principio de igualdad en el que creía". (2001, p.139).

Por otro lado, István Mészáros (2007) nos recuerda tanto a Lenin como a Babeuf, como dos figuras preocupadas por la igualdad. Acerca de Lenin, invoca que no sólo le importaba la igualdad de los grupos nacionales, sino también de tornar "desigual la igualdad" en favor de los que estaban en desventaja o eran oprimidos, retomando el punto de vista marxiano en esto. Asimismo, acerca de François Babeuf, anota que éste definió las condiciones de igualdad con base en las necesidades humanas. Así la igualdad fue defendida en el campo de la izquierda desde la época de la Revolución Francesa.

En ese sentido, el ideal moderno de igualdad - como dice Alex Callinicos (2003) - posee un significado histórico preciso en las revoluciones burguesas de los siglos XVII y XVIII, en el socialismo emergente de esas condiciones, y especialmente en el socialismo moderno surgido después de la revolución francesa, en el que se distinguen claramente dos alas: la del socialismo utópico de Saint-Simon, Fourier y Robert Owen y el ala del

${ }^{5}$ Recordemos que John Rawls inaugura todo un debate acerca de la justicia al interior de la filosofía política, una vez salida a luz su obra La Teoría de la Justicia en 1971. 
comunismo revolucionario de Graco Babeuf y Augusto Blanqui. Para Callinicos (2004) el punto de partida de los utópicos fue la inconsistencia entre las aspiraciones de libertad, igualdad y fraternidad de la revolución y las realidades del capitalismo de la Francia post revolucionaria. El socialismo se constituyó en el horizonte societario a construir, y en estos socialistas ya se visualizaba la preocupación por la manera que debía adquirir la distribución de los bienes y recursos sociales en esa nueva sociedad, lo que posteriormente Marx (1979) recogería en la Crítica del Programa de Gotha. ${ }^{6}$ El grupo de Saint-Simon planteaba que bajo el socialismo la distribución sería regida por el principio de "Cada cual según su capacidad, a cada cual según su trabajo", esto es, la idea de que reciben más aquellas personas con más destrezas o talento a diferencia de la posición de Louis Blanqui cuyo lema igualitario era "de cada cual según su capacidad, a cada cual según sus necesidades".

Según Gian Bravo (1997) los precursores del socialismo - como Babeuf y Buonarroti - apelan al comunitarismo y a la igualdad, proponiendo una transformación radical de la sociedad. Babeuf influido, tanto por los escritos de Rousseau como por el desarrollo de las masas y sectores de trabajadores parisinos, saca a luz un proyecto de transformación social y política, que expresa en el Manifiesto de los Iguales ${ }^{7}$ de 1797, especie de programa socialista que tendría gran influencia hasta la aparición del Manifiesto Comunista en 1848. El texto enfatiza la igualdad substantiva y no la igualdad formal. La primera se entiende como aquella que anula la diferencia entre rico y pobre, grandes y chicos, gobernado y gobernante, e iguala las necesidades que deben y precisan cubrir todos los hombres. La propuesta de Babeuf, posteriormente será leída - según Bravo - en clave de lucha de clases, quedando así vinculada al plan de la conquista del poder mediante la insurrección popular.

Federico Engels, no fue ajeno al intento de comprensión teóricopolítica de ésta que ratificaba en el Anti Dühring, publicado en 1878. En

\footnotetext{
${ }^{6}$ El trabajo de Marx Crítica del Programa de Gotha, hace observaciones críticas al proyecto del futuro partido obrero unificado de Alemania. Fue expuesta por Marx en su carta a Bracke, del 5 de mayo de 1875, pero editada por NeueZeiten 1891. A finales de la década de los 60 del siglo XIX, los dirigentes más importantes de la socialdemocracia alemana eran W. Liebknecht y A. Bebel, que encabezaban el Partido Obrero Socialista.

${ }^{71}$ ¡ La igualdad! ¡Voto primero de la naturaleza, necesidad primera del hombre, primer elemento de toda asociación legítima!... Desde tiempo inmemorial se repite hipócritamente que los hombres son iguales; $y$ desde tiempo inmemorial pesa inexorablemente sobre el género humano la desigualdad más vil y monstruosa. Desde que existen las sociedades civiles, la prenda más bella del hombre ha sido reconocida sin oposición, pero aún no ha podido realizarse ni una sola vez: la igualdad no fue otra cosa que una ficción, tan bella como estéril, de la ley. Hoy reivindicada por una voz más potente, la respuesta es: ¡Calláos, miserables! La igualdad relativa: todos sois iguales ante la ley. Canallas ¿qué más queréis? ¿Qué es lo que queremos? Legisladores, gobernantes, ricos propietarios escuchadnos ahora... Y bien, lo que queremos es vivir y morir iguales, tal como hemos nacido: queremos la igualdad efectiva, o la muerte $(. .$.$) ; Que$ se acabe este gran escándalo, al que nuestros descendientes no querrán prestar fé! Desapareced, finalmente, desagradables distinciones entre ricos y pobres, grandes y pequeños, amos y siervos, gobernantes y gobernados. Que entre los hombres no haya más diferencias que las de edad y sexo. Pues que todos tienen las mismas necesidades y las mismas facultades, que no haya para ellos más que una sola educación y que un solo alimento. Todos se conforman con un único sol y con un solo aire: ipor qué las mismas cualidad y cantidad de alimento no deberían bastar a cada uno de los hombres?... Ha llegado el momento de fundar la República de los Iguales, este gran refugio abierto a todos los hombres" (BRAVO, 1997, p.12-13).
} 


\section{AeVistg all paUtg}

\} APORTES MARXISTAS PARA LA COMPRENSIÓN CONTEMPORÁNEA - MOLINA, P. V. \}

este texto, reconoce que la igualdad no solo alcanzó - con Rousseau - el nivel de categoría teórica, sino también fue capaz de acompañar la práctica política de la Revolución Francesa, pues fue una idea valorada como herramienta de agitación de los proletarios y del movimiento socialista de varios países.

Engels no se equivocaba al afirmar que la idea de que existe algo en común entre los hombres, que los hace ser iguales, es muy antigua; sin embargo, sólo en la modernidad deriva la idea hacia el principio de una igualdad política y social de todos los seres humanos dentro de la sociedad y del Estado. Según Engels, esta idea no habría sido nada natural ni evidente para la antigua Grecia, Roma y el cristianismo. ${ }^{8}$ A partir del feudalismo y a medida que se iba gestando la burguesía, sería este segmento social el que levantaría luego el "moderno postulado de la igualdad".

Siguiendo a Engels, el desarrollo comercial requería que hubiera propietarios de mercancías, libres para hacer todo tipo de transacciones dentro de un marco de derechos igual para todos. El paso de los artesanos a obreros implicó que quedaran libres de las trabas gremiales y de los medios necesarios para explotar por sí mismos su fuerza de trabajo. Bajo tales condiciones, podían celebrar un contrato de "igual a igual" con el fabricante, al venderle a su fuerza de trabajo. El progreso económico fue de la mano con la emancipación de las trabas feudales y de la implantación de la igualdad jurídica, pero la igualdad jurídica escondía la desigualdad real entre empresario y proletario. El desarrollo del proletariado y su lucha, denunció esta desigualdad e hizo ver la necesidad de restablecer una igualdad real en los planos económico y social.

En Engels, entonces, la igualdad - como principio del proletariado - posee una doble acepción. Por un lado, brota como reacción revolucionaria contra las desigualdades sociales del momento histórico; y por otro, fue una reacción contra el postulado de igualdad de la burguesía, sacando de ella reivindicaciones más avanzadas (pues las afirmaciones burguesas se tornan falsas). Así, el sentimiento producido por las desigualdades sociales y los límites de la igualdad burguesa, permitiría que la lucha de los obreros fuera a favor de la abolición de las clases sociales. Así, la idea de igualdad - en su hechura burguesa y también en la proletaria - no podía darse sino como producto histórico, capaz de mantenerse debido a la divulgación, aceptación y actualidad (de ese momento histórico) de las ideas del siglo XVIII entre las masas, la igualdad

\footnotetext{
8 "En las más antiguas comunidades primitivas, sólo podía hablarse de igualdad, a lo sumo, entre los miembros de la misma comunidad; las mujeres, los esclavos, los forasteros, quedaban excluidos, naturalmente, de esa igualdad. En Grecia y en Roma, las desigualdades entre los hombres tenían mucha más fuerza que cualquier género de igualdad [...] El cristianismo solo reconocía una igualdad entre los hombres: la del pecado original, igualdad que cuadraba perfectamente a su carácter de religión de los esclavos y los oprimidos. Al lado de ésta, admitía a lo sumo la igualdad de los elegidos, pero sólo muy en sus comienzos hizo hincapié en ella. Las huellas de comunidad de bienes con que nos encontramos igualmente en los primeros tiempos de la nueva religión, tenían su origen más bien en la solidaridad de los proscriptos, que en una verdadera idea de igualdad. Pero muy pronto, la comprobación de la diferencia entre sacerdotes y legos vino a poner fin a este rudimento de igualdad cristiana". (ENGELS, 1975, p.127).
} 
si hoy es ya algo evidente para el gran público - en un sentido o en otro -, si como dice Marx, "posee ya la estabilidad de un prejuicio popular", no es por la virtud de su verdad axiomática, sino por obra de la difusión general y de la persistente actualidad de las ideas del siglo XVIII. (ENGELS, 1975, p.131).

La igualdad - como ideal de la burguesía - se extendió más allá, sobrepasándose a sí misma en su sentido original, permitiendo construir el ideal proletario y teniendo como límite sólo alcanzar la igualdad de clase, pues aspirar a la igualdad en otro plano era inconcebible para Engels.

Marx (2008), por su lado, al hacer su crítica del capitalismo como un sistema centrado profundamente en la explotación y crónicamente propenso a las crisis, aporta elementos - en El Capital - para establecer relaciones entre las desigualdades y la estructura económica del capitalismo (relaciones que no han sido por naturaleza igual en todos los períodos históricos), y ello aparece cuando al dar cuenta de la lógica del modo de producción capitalista, menciona la producción de plusvalor como su eje central;

La fuerza de trabajo no se compra aquí para satisfacer, mediante sus servicios o su producto, las necesidades personales del comprador. El objetivo perseguido por éste es la valorización de su capital, la producción de mercancías que contengan más trabajo que el pagado por él, o sea que contengan una parte de valor que nada le cuesta al comprador y que sin embargo, se realiza mediante la venta de las mercancías. La producción de plusvalor, el fabricar un excedente, es la ley absoluta de este modo de producción. Sólo es posible vender la fuerza de trabajo en tanto la misma conserva como capital los medios de producción, reproduce como capital su propio valor y proporciona, con el trabajo impago, una fuente de pluscapital. (MARX, 2008, p.767).

La relación e intercambio entre comprador y vendedor de fuerza de trabajo, precisa de la condición de que cada uno de ellos sea un propietario libre y de la igualdad de derechos, capaces de intercambiar en el mercado sus propias mercancías,

El intercambio de mercancías, en sí y para sí, no implica más relaciones de dependencia que las que surgen de su propia naturaleza. Bajo este supuesto, la fuerza de trabajo, como mercancía, sólo puede aparecer en el mercado en la medida y por el hecho de que su propio poseedor - la persona a quien pertenece esa fuerza de trabajo - la ofrezca y venda como mercancía. Para que su poseedor la venda como mercancía es necesario que pueda disponer de la misma, y por tanto que sea propietario libre de su capacidad de trabajo, de su persona. Él y el poseedor de dinero se encuentran en el mercado y traban relaciones mutuas en calidad de poseedores de mercancías dotados de los mismos derechos, y que sólo se distinguen por ser el 
uno vendedor y el otro comprador; ambos, pues, son personas jurídicamente iguales. Para que perdure esta relación es necesario que el poseedor de la fuerza de trabajo la venda siempre por un tiempo determinado, y nada más, ya que si la vende toda junta, de una vez para siempre, se vende a sí mismo, se transforma de hombre libre en esclavo, de poseedor de mercancías en simple mercancía. (MARX, 2008, p.203-204).

La condición - sigue Marx - para que sea posible encontrar en el mercado la fuerza de trabajo como mercancía es que el poseedor de ésta se encuentre desprovisto de medios de producción y medios de subsistencia,

Para la transformación del dinero en capital el poseedor de dinero, pues, tiene que encontrar en el mercado de mercancías al obrero libre; libre en el doble sentido de que por una parte dispone, en cuanto hombre libre, de su fuerza de trabajo en cuanto mercancía suya, y de que, por otra parte, carece de otras mercancías para vender, está exento y desprovisto, desembarazado de todas las cosas necesarias para la puesta en actividad de su fuerza de trabajo. (MARX, 2008, p.205).

La crítica profunda de Marx en El Capital pone al descubierto la raíz de la desigualdad, develando con ello lo que encubre la relación entre trabajador y capitalista. En el contrato que realizan trabajador y capitalista, transacción que se realiza en la esfera de la "circulación de las mercancías", es donde se observa una igualdad formal entre ambos, pero una vez que el trabajador vuelve al "domicilio oculto de la producción" la igualdad formal cambia, quedando al descubierto la desigualdad entre trabajador y capitalista. Por lo tanto, "la aparente libertad e igualdad del trabajador respecto al capitalista oculta una subordinación y desigualdad cuyo resultado es la explotación del primero." (CALLINICOS, 2003, p.41). El trabajador, dada su desposesión de los medios de producción y la mala distribución de éstos, se ve obligado - en definitiva - no vender su fuerza de trabajo por opción, sino porque de no hacerlo corre el riesgo de morir de hambre.

En la Crítica del Programa de Gotha, escrito en 1875 y aparecido en 1891, Marx (1979) formula dos principios -el de contribución y el de necesidad - que orientarán una sociedad igualitaria futura, después de destruido el sistema capitalista, y comenzada la transición hacia la sociedad comunista.

El principio "a cada cual según sus necesidades" deberá ser el criterio que oriente la distribución de los bienes y recursos en la nueva sociedad, después que hayan sido superadas la esclavitud de los seres humanos, el sometimiento a la división del trabajo, la diferencia entre trabajo intelectual y trabajo manual. Esto deberá suceder, según Marx, en la última etapa de la transición del socialismo al comunismo (por medio de la dictadura del proletariado). Para entonces, habrán aumentado las fuerzas pro- 


\section{Revista pll paעtg}

\} APORTES MARXISTAS PARA LA COMPRENSIÓN CONTEMPORÁNEA - MOLINA, P. V.\}

ductivas, y habrá seguridad de la abundancia de productos y bienes, lo que permitirá que cada persona reciba lo que necesita. En esta sociedad existirán fondos públicos, para garantizar las inversiones o financiar los servicios sociales para asegurar la protección a los que no pueden trabajar.

En una fase superior de la sociedad comunista, cuando haya desaparecido la subordinación esclavizadora de los individuos a la división del trabajo, y con ella, el contraste entre el trabajo intelectual y el trabajo manual; cuando el trabajo no sea solamente un medio de vida, sino la primera necesidad vital; cuando, con el desarrollo de los individuos en todos sus aspectos, crezcan también las fuerzas productivas y corran a chorro lleno los manantiales de la riqueza colectiva, sólo entonces podrá rebasarse totalmente el estrecho horizonte del derecho burgués y la sociedad podrá escribir en sus banderas: ¡De cada cual, según sus capacidades; a cada cual según sus necesidades. (MARX, 1979).

Marx agrega que debido a que la sociedad comunista no nace de sí misma, sino que surge desde las mismas entrañas del capitalismo, acarrea consigo aspectos económicos, morales e intelectuales de aquella sociedad, por lo que en una primera etapa de transición, - la socialista - tendrá cabida el derecho burgués, es decir donde los productores aportarán cierta cantidad y tipo de trabajo y recibirán de la sociedad una retribución en medios de consumo equivalente a su aporte, pero descontado el trabajo que realizan para el fondo común de la sociedad. Es lo que Marx Ilama, un intercambio de equivalentes al trabajo que ha rendido el productor, eso sí variando en forma y contenido al existente en la sociedad capitalista,

Aquí reina, evidentemente, el mismo principio que regula el intercambio de mercancías, por cuanto éste intercambio de equivalentes. Han variado la forma y contenido, porque bajo las nuevas condiciones nadie puede dar sino su trabajo, y porque, por otra parte, nada puede pasar a ser propiedad del individuo, fuera de los medios individuales de consumo. Pero, en lo que se refiere a la distribución de éstos entre los distintos productores, rige el mismo principio que en el intercambio de mercancías equivalentes: se cambia una cantidad de trabajo, bajo una forma, por otra cantidad de igual trabajo, bajo otra forma distinta. (MARX, 1979).

Marx rechaza el hincapié que hacen los socialistas vulgares en la distribución de los medios de consumo como si ello fuera lo más importante, sin considerar la propiedad de los medios de producción. Esta forma de consideración sólo lleva a limitar las demandas a la reforma parcial, lo cual se aleja de la transformación radical del capitalismo. Para esto último se necesita reconocer que "la distribución de los medios de consumo es, en todo momento, un corolario de la distribución de las propias condiciones de producción". (MARX, 1979). 


\section{ReVistg all paUtg}

\} APORTES MARXISTAS PARA LA COMPRENSIÓN CONTEMPORÁNEA - MOLINA, P. V. \}

El otro principio, el de contribución, considera la diferencia de los aportes de los trabajadores. Sobre ello reflexiona Marx (1979) en "La crítica del Programa de Gotha". Al tomar en cuenta esa diferencia, se ve que Marx no entiende a la igualdad como una condición o criterio a ser aplicado de manera uniforme a todos los trabajadores. Sin embargo, el principio de contribución posee la limitación de tratar de igual manera, es decir, de aplicar la misma medida, esto es el trabajo, a sujetos que son física e intelectualmente diferentes entre sí y que rinden diferenciadamente, pero además ¿de qué trabajo se trata?, ¿cómo se mide el trabajo?, ¿será que se mide como el tiempo de trabajo?, pero ¿de qué o cuál trabajo?, preguntas que no quedan claras en la exposición de Marx, pero criterio que considera, finalmente, posee limitaciones serias para concretar la igualdad en una sociedad comunista,

A pesar de este progreso, este derecho igual sigue llevando implícita una limitación burguesa. El derecho de los productores es proporcional al trabajo que han rendido; la igualdad, aquí, consiste en que se mide por el mismo rasero: por el trabajo. Pero unos individuos son superiores física o intelectualmente a otros y rinden, pues, en el mismo tiempo, más trabajo, o pueden trabajar más tiempo; y el trabajo para servir de medida tiene que determinarse en cuanto a su duración o intensidad; de otro modo deja de ser una medida. Este derecho igual es un derecho desigual para trabajo desigual. (MARX, 1979).

En esta primera fase - socialista - la cuestión de la propiedad privada de los medios de producción es algo superado, por lo que la distinción de clases no tiene sentido, pero coexiste con el derecho, que en esta etapa no diferencia entre clases, sino que considera a todos como trabajadores que poseen una desigual capacidad, aptitud y por lo mismo, rendimiento. El derecho aquí es la aplicación de una misma medida, que debería ser aplicada a un aspecto específico, y por lo mismo, sigue siendo insuficientemente igualitario, porque trata de igual modo lo que es desigual, en ese sentido Marx plantea que el derecho tendría que ser desigual, es decir, capaz de captar la diferencia que cada trabajador contempla,

No reconoce ninguna distinción de clase, porque aquí cada individuo no es más que un obrero como los demás; pero reconoce, tácitamente, como otros tantos privilegios naturales, las desiguales aptitudes de los individuos, y, por consiguiente, la desigual capacidad de rendimiento. En el fondo es, por tanto, como todo derecho, el derecho de la desigualdad. El derecho sólo puede consistir, por su naturaleza, en la aplicación de una medida igual; pero los individuos desiguales (y no serían distintos individuos si no fuesen desiguales) sólo pueden medirse por la misma medida siempre y cuando que se les enfoque desde un punto de vista igual, siempre y cuando se les mire solamente en un aspecto determinado; por ejemplo, en el caso concreto, sólo en cuanto obreros, y no se vea en ellos ninguna otra cosa, es decir, 
se prescinda de todo lo demás. Prosigamos: unos obreros están casados y otros no; unos tienen más hijos que otros, etc. A igual trabajo y, por consiguiente, a igual participación en el fondo social de consumo, unos obtienen de hecho más que otros, etc. Para evitar todos estos inconvenientes, el derecho no tendría que ser igual, sino desigual. (MARX, 1979)

\section{A modo de conclusión para seguir el debate: desigualdad en la igualdad marxiana}

La crítica de Marx al principio de contribución, según Callinicos (2003), no debe ser comprendido como un rechazo a todos los principios de igualdad, sino como un rechazo del principio de contribución por ser éste insuficientemente igualitario, a diferencia del principio de necesidad que - según Callinicos - es un principio de igualdad refinado porque toma en consideración todas las diferencias por las que deberían ser compensados los sujetos. Así la diferencia sería contenida en la igualdad.

Estos dos criterios o principios de distribución de bienes y recursos en las diversas fases de una sociedad postcapitalista - el de contribución como "de cada cual según su trabajo" y el de necesidad como "a cada cual según sus necesidades" (CALLINICOS, 2003, LIZÁRRAGA, 2004).

En un contexto de transición hacia una sociedad comunista, se parte desde el principio de contribución como un criterio de distribución aplicable en la sociedad socialista (en que se expresan aún los resabios de una sociedad burguesa), donde los individuos pueden gozar o beneficiarse inmerecidamente de su capacidad laboral y desempeño en el trabajo, derivados de los privilegios de los individuos, tanto de orden natural - inteligencia o capacidad física - como también social - educación o crianza -, y de lo que no son moralmente responsables ellos mismos. Por lo tanto, este criterio es deficientemente igualitario porque al permitir aprovechar las ventajas inmerecidas (sus talentos) mediante el desempeño del trabajo, legitima así la propiedad individual (su acumulación) y las preferencias egoístas, prescindiendo de un ethos igualitario (LIZÁRRAGA, 2004). El trabajo, en este principio no es parte de un acervo común que se pone a disposición de la sociedad.

En cuanto se avanza hacia la etapa de la sociedad comunista, el principio de necesidad es la expresión de una mayor complejidad en la distribución al interior de una sociedad, sociedad en la que se habrán desarrollado las fuerzas productivas, la riqueza y un ethos colectivo, que permitirá dar cumplimiento a la distribución según las diferentes necesidades de cada sujeto. En esta etapa es donde las necesidades limitan a las necesidades, pues la producción de los sujetos es para sus necesidades y éstas se ajustan a las definidas democráticamente y se han hecho parte del ethos 


\section{AeVistg all paUtg}

\} APORTES MARXISTAS PARA LA COMPRENSIÓN CONTEMPORÁNEA - MOLINA, P. V. \}

social, que pone en el centro la autorrealización de cada individuo, sobre la base de la abundancia material suficiente como para satisfacer necesidades razonables y lejos de los intereses egoístas (LIZÁRRAGA, 2004).

Marx, entonces reconoce la situación de igualdad y desigualdad de hombres y mujeres, donde cada uno, siendo diferente - en cuanto a sus dotes físicas, emocionales y psicológicas - poseen un núcleo de necesidades materiales y culturales (o espirituales) comunes a todos.

Ambos criterios formarían la noción de igualdad, la cual sería parte de una implícita teoría de la justicia en Marx, o como dice Callinicos (2003, p.41) "podría considerarse como la base de su teoría de la justicia". A pesar de la enemistad de Marx con los conceptos normativos, esta interpretación de los escritos de Marx, fue puesta - y de alguna forma aceptada desde hace un tiempo - por una parte de estudiosos de la obra de Marx y que la conciben en el camino de la justicia y la ética. Un artículo de Norman Geras publicado en el año 1985 marca un punto de inflexión en este asunto, pues al repasar los argumentos y contra-argumentos sobre la tesis de que Marx habría criticado el capitalismo como injusto, encontró evidencia textual en uno y otro sentido. Dicho artículo marca un hito en las búsquedas y preocupaciones que vienen teniendo varios marxistas, entre ellos también los marxistas analíticos (GARGARELLA, 1999) y quienes se preguntan por la dimensión ética del marxismo.

El artículo de Norman Geras titulado The controversy about Marx and Justice, ${ }^{9}$ afirma que la forma en que Marx analiza y describe la relación entre la explotación capitalista y la desigual distribución de bienes, muestra signos de una condena al capitalismo. ${ }^{10}$ Por ello, el tratamiento que realiza acerca de la explotación hace suponer que "Marx pensaba, efectivamente, que el capitalismo era injusto, pero no pensaba que pensara eso" (GERAS, 1985). En ese sentido existiría implícitamente una teoría de la justicia en Marx. Según Callinicos, Marx contaba con una errónea teoría metaética, que le impedía "ver los principios morales universales como algo distinto a la expresión de intereses de clase históricamente específicos y, por tanto, reconocerlos como la base desde la que él mismo condenaba la explotación capitalista" (CALLINICOS, 2003, p.42). Como dice Lizárraga, esta interpretación que se hace de Marx, junto con sus dos principios (comprendidos como un igualitarismo complejo), tal vez no estaría dispuesto el mismo Marx a admitirla, pero "afirmar que Marx no condenaba al capitalismo por sus injusticias contradice nuestras intuiciones fundamentales sobre el proyecto emancipatorio comunista" (LIZÁRRAGA, 2004, p.27). No obstante, más

\footnotetext{
${ }^{9}$ En este artículo, publicado en la New Left Review en 1985, explicita que su estudio revisa cerca de tres docenas de artículos de autores pertenecientes al mundo anglosajón, de ellos repasa los argumentos que niegan que Marx condenó al capitalismo como injusto, lo mismo hace con los que afirman que éste si lo hizo, y con aquellos que toman una posición intermedia, llegando luego a su propia interpretación.

${ }^{10}$ Norman Geras en un artículo titulado "Bringing Marx to justice: anaddendum and rejoinder" publicado también en la New Left Review en 1992, retoma la polémica suscitada en 1985 y mantiene su postura, incorporando mucha más literatura al respecto - como evidencia - del debate acerca de si Marx condenó o no el capitalismo como injusto.
} 


\section{Revigtg all palth}

[ APORTES MARXISTAS PARA LA COMPRENSIÓN CONTEMPORÁNEA - MOLINA, P. V. \}

allá de la polémica acerca de la existencia o no de una teoría de la justicia, o de la dimensión normativa en los escritos de Marx, lo que parece seguro es que ambos principios se orientan hacia la autorrealización de los individuos al interior de una comunidad y a la igualdad de realización de las diversas necesidades de los individuos sobre la base de la abundancia material y un ethos colectivo.

Después de lo señalado, podemos afirmar que al realizar un bosquejo de la nueva sociedad no se puede prescindir del aporte de Marx en lo que a la crítica de raíz de la sociedad contemporánea compete, y la noción de Igualdad es fundamental en esto. Sin igualdad radical, no es posible una sociedad emancipada, o dicho de otro modo, a mayor igualdad en la sociedad, menos capitalismo.

Ayer, la clase trabajadora tomó las banderas de la Igualdad en la lucha por la emancipación, hoy lo hacen los jóvenes, estudiantes, y trabajadores chilenos. 


\section{ReVistg all paUtg}

\} APORTES MARXISTAS PARA LA COMPRENSIÓN CONTEMPORÁNEA - MOLINA, P. V.\}

\section{Referências}

ANDERSON, P. Consideraciones del marxismo occidental. México: Siglo XXI, 2005.

Más allá del neoliberalismo: lecciones para la izquierda. In: SADER, E.; GENTILI, P. (Comp.). La trama del neoliberalismo: mercado, crisis y exclusión social. Buenos Aires: Clacso, 2003.

BENSAÏD, D. Potencias del comunismo. Editado en Viento Sur, n.108, 2009. Disponible en: <http://www.vientosur.info/articulosweb/noticia/index. php?x=2711>. Acceso en: 1 jun. 2010.

BOBBIO, N. Derecha e izquierda: razones y significados de una distinción política. Madrid: Santillana Taurus, 1996.

BRAVO, G. El primer socialismo: temas, corrientes y autores. Madrid: Akal, 1998.

CALLINICOS, A. Igualdad. Madrid: Siglo XXI, 2003.

. The revolutionary ideas of Karl Marx. Londres: Bookmarks Publication, 2004.

COHEN, G. ¿Por qué no el socialismo? Madrid: Katz Editores, 2011.

. Si eres igualitarista, ¿cómo es que eres tan rico? Barcelona: Paidós, 2001.

EAGLETON, T. Después de la teoría. Barcelona: Debate, 2005.

Un futuro para el socialismo. In: BORÓN, A.; AMADEO J.; GONZÁLEZ, S. (Comp.). La teoría marxista hoy: problemas y perspectivas. Buenos Aires: Clacso, 2006.

ENGELS, F. El Anti Dühring. La Habana: Pueblo y Educación, 1975.

GARGARELLA, R. Las teorías de la justicia después de Rawls: un breve manual de filosofía política. Barcelona: Paidós, 1999.

GERAS, N. Bringing Marx to justice: an addendum and rejoinder. New Left Review I/195, Sep./Oct. Londres: 1992

. The controversy about Marx and justice. New Left Review I/150, mar-apr. Londres: 1985.

HOBSBAWN, E. Historia del siglo XX. Buenos Aires: Crítica, 2006.

JAMESON, F. O marxismo realmente existente. Espaço e Imagem. Río de Janeiro: UFRJ, 2004.

LIZÁRRAGA, F. Principios de justicia en el pensamiento de Ernesto Che Guevara. Tesis Doctoral en Ciencias Sociales. Universidad de Buenos Aires, 2004. 


\section{Revigtg all palth}

\} APORTES MARXISTAS PARA LA COMPRENSIÓN CONTEMPORÁNEA - MOLINA, P. V.\}

LOSURDO, D. Hegel, Marx e a tradição Liberal: liberdade, igualdade, Estado. São Paulo: UNESP, 1998.

LÖWY, M. Marx un siglo después. El Rodaballo, Revista de cultura y política. Año 1, n. 1, nov. 1994. Disponible en: <http://www.nodo50.org/rebelde mule/foro/viewtopic.php?f=19\&t=7988>. Acceso en: ago. 2009.

O marxismo na América Latina: uma antologia de 1909 aos dias atuais. São Paulo: Fundação Perseu Abramo, 2006.

Walter Benjamin: aviso de incendio. México: Fondo de Cultura Económica, 2003.

MARX, K. El Capital. Libro Primero. Tomo 1 y 3. Buenos Aires: Siglo XXI, 2008.

2008 .

El Dieciocho Brumario de Luis Bonaparte. Santiago: Quimantú,

. Crítica del Programa de Gotha. In: MARX, K.; ENGELS, F. Obras Escogidas. Pekín: Ediciones en lenguas extranjeras 1979. ARCHIVO MarxEngels en español. Disponible en: <http://www.marxists.org/espanol/m-e/ index.htm>.

MESZAROS, I. O poder da ideología. Brasil: Boitempo, 2004.

SINGER, D. ¿Quién dominará el milenio, ellos o nosotros? México: Siglo XXI, 2000.

Recebido em 06 de outubro de 2014.

Aprovado para publicação em 25 de novembro de 2014. 